\title{
ASPECTOS DEL OCIO Y DE LA OCIOSIDAD EN EL TEATRO Y EN EL DISCURSO SOBRE EL TEATRO DIECIOCHESCO ESPAÑOL
}

\author{
Aspects of Leisure and Idleness in the Theatre and the \\ Discourse about the Theatre in Eighteenth-Century Spain
}

\author{
Christian von TSCHILSCHKE \\ Universität Siegen \\ tschilschke@romanistik.uni-siegen.de
}

Fecha de recepción: 8/01/2018

Fecha de aceptación definitiva: 18/02/2018

RESUMEN: Este artículo expone la compleja relación entre el ocio y su complemento negativo, la ociosidad, en el teatro dieciochesco español distinguiendo dos niveles: el discurso sobre el teatro y las mismas representaciones teatrales realizadas en varios subgéneros (comedia neoclásica, drama sentimental, sainete). En cuanto a las discusiones controvertidas sobre el teatro, se hacen notar posiciones que identifican el ocio con la ociosidad, otras que separan ambos nítidamente y hay quienes instrumentalizan el uno para combatir el otro. En la práctica teatral de orientación neoclásica, sin embargo, domina la censura moral de la ociosidad desde una nueva ética del trabajo que implica, al mismo tiempo, una revaloración del ocio como descanso merecido y revitalizante. De todo modo, las negociaciones entre el ocio y la ociosidad que operan mediante las teorías y prácticas del teatro durante la segunda mitad del siglo resultan un importante indicador de los cambios éticos, estéticos y sociales de la época.

Palabras clave: teatro; comedia neoclásica; ocio; ociosidad; Jovellanos; segunda mitad del siglo XVIII.

ABSTRACT: This article exposes the complex relationship between leisure and its negative complement, idleness, in eighteenth-century Spanish theatre 
distinguishing two levels: the discourse about the theatre and the theatrical representations themselves, realized in different subgenres (neo-classic drama, sentimental drama, sainete). With regard to the controversial discussions about the theatre, several positions can be identified: either is leisure equated with idleness, or the two are clearly seperated from each other or the one is instrumentalized in order to fight the other. In the practice of neoclassical theatre, however, the moral censure of idleness inspired by a new ethics of work that implies the enhancement of leisure as a well deserved rest and revitalization prevails. In any case, the negotiations between leisure and idleness within the theoretical discussions of the theatre and its realization in practice during the second half of the eighteenth century turn out to be an important indicator of the ethic, aesthetic and social changes that mark the epoch.

Key words: Theatre; neo-classic drama; leisure; idleness; Jovellanos; second half of the eighteenth century.

\section{INTRODUCCIÓN: EL CAMBiO DE LA CULTURA ESPAÑOLA EN EL SIGLO DIECIOCHO}

Al enfocar algunos aspectos de un tema tan amplio y trascendente como el ocio y la ociosidad en relación con el teatro dieciochesco español y con la manera en que se reflexionó sobre estos aspectos en esa época, el interés se centra decididamente en la esfera pública y "la diversión masiva y tradicional del español, independientemente de su nivel social ${ }^{1}$ o educativo. Como principal expresión y manifestación cultural del ocio en el sentido neutro y descriptivo de la palabra, "cesación del trabajo», "tiempo libre» o «diversión", así como medio predilecto de la transmisión de normas sociales y de la denuncia de la ociosidad como «vicio de no trabajar, perder el tiempo o gastarlo inútilmente», según las definiciones más recientes de la 22. ${ }^{a}$ edición del Diccionario de la Real Academia Española del año $2012^{2}$, el teatro y los espectáculos teatrales constituyen, evidentemente, un objeto clave para la discusión de la diferencia básica entre ocio y ociosidad en el siglo dieciocho.

Esta constatación vale aún más si se tiene en cuenta que las discusiones sobre el teatro y las diferentes reformas o proyectos de reforma del ámbito teatral representan, como es sabido, una de las mayores preocupaciones de los literatos, intelectuales y políticos a lo largo de todo el siglo ${ }^{3}$. Estas discusiones estéticas y

1. SÁnChez-Blanco, Francisco. El Absolutismo y las Luces en el reinado de Carlos III. Madrid: Marcial Pons, 2002, p. 149.

2. http://lema.rae.es/drae/. Las definiciones que ofrece el tomo V del Diccionario de Autoridades (1737) no difieren mucho de las explicaciones actuales: "cessación del trabajo, inacción o total omissión de hacer alguna cosa» (para "Ocio») y "el vicio de perder o gastar el tiempo inútilmente» (para "Ociosidad») (http://web.frl.es/DA.html).

3. Consúltense al respecto, entre otros: ANDIOC, René. Teatro y Sociedad en el Madrid del siglo XVIII. 2. ${ }^{a}$ ed. corregida y aumentada. Madrid: Castalia, 1987; COOK, John A. Neo-classic Drama in Spain. Theory and Practice. Dallas: Southern Methodist University Press, 1959; Rubio Jiménez, Jesús. El conde 
políticas, tan fervientes que se ha convenido en llamarlas una verdadera «batalla del teatro" ${ }^{4}$, son uno de los síntomas más obvios del cambio fundamental al que está sometida la cultura española de la época. En su introducción a la obra colectiva The Institutionalization of Literature in Spain, Wlad Godzich y Nicholas Spadaccini interpretan este cambio como un proceso de monologización e institucionalización paulatina del discurso literario. Consideran la literatura española de la Edad Media y de los Siglos de Oro como polífona, caracterizada por un discurso de permeabilidad entre la cultura del pueblo y de las élites. Sin embargo, durante el siglo XVIII, debido no solo a los esfuerzos de los mismos protagonistas del movimiento ilustrado y del gobierno, este discurso adquiere, según los autores, una naturaleza monóloga, institucionalizada y nacionalista; de modo que, dentro de este proceso, se abre una fisura significativa entre la cultura alta y la cultura baja5.

Aunque la importancia central del teatro como institución moral pública en el marco de esta cultura expuesta a la intervención y al control estatal ya haya sido tratada y comentada a fondo ${ }^{6}$, puede sorprender que en este contexto la cuestión del ocio y de la ociosidad, al menos a mi parecer, hasta la fecha nunca ha formado el objeto explícito de un estudio particular ${ }^{7}$. Y eso a pesar de que la dimensión del ocio y de la ociosidad está involucrada en ese proceso a todos los niveles aunque en la mayoría de los casos de modo implícito o indirecto. Así, la oposición estética, moral e incluso a veces política entre los defensores de la tradición barroca y los novadores neoclásicos que marca todo el siglo implica distintas concepciones generales de la función social del teatro y, al mismo tiempo y consustancial a ella, de la manera de hacer un buen o un mal uso del tiempo libre, o sea, de convertir el ocio en ociosidad. Es evidente que mediante la evocación del ocio y del uso respectivo que se hace de él se negocian asuntos tan fundamentales como las

de Aranda y el teatro. Zaragoza: Caja de Ahorros de Piedad de Zaragoza, Aragón y Rioja, 1998 y la síntesis en el capítulo VI de CARnero, Guillermo (ed.). Historia de la literatura española. Siglo XVIII, tomo II. Madrid: Espasa-Calpe, 1995, pp. 413-485.

4. Sobre los aspectos políticos y anticlericales del debate se pueden consultar DOMínguEZ OrTIZ, Antonio. «La batalla del teatro en el reinado de Carlos III (I)». Anales de Literatura Española, 1983, 2, pp. 177-196 y, con un particular enfoque sobre la situación en Andalucía, Domínguez OrTIZ, Antonio. "La batalla del teatro en el reinado de Carlos III (II)». Anales de Literatura Española, 1984, 3, pp. 207-234.

5. Véanse Godzich, Wlad y SPADAccini, Nicholas (eds.). "Introduction. From Discourse to Institution". En GODZICH, Wlad y SPADACCINI, Nicholas (eds.). The Institutionalization of Literature in Spain. Minneapolis: The Prisma Institute, 1987, pp. 9-38; pp. 10-17.

6. Véanse, por ejemplo, los siguientes estudios elementales: MARAVALL, José Antonio. "La función educadora del teatro en el siglo de la Ilustración" (1982). En Maravall, José Antonio. Estudios de la historia del pensamiento español (siglo XVIII). Editado por María del Carmen Iglesias. Madrid: Mondadori, 1991, pp. 382-406 y Maravall, José Antonio. "Política directiva en el teatro ilustrado» (1988). En Maravall, José Antonio. Estudios... Op. cit., pp. 524-536.

7. Este aspecto tampoco se trata en la publicación más reciente dedicada a la compleja relación entre ocio y ociosidad en el siglo XVIII español, FAJEN, Robert y GELZ, Andreas (eds.). Ocio y ociosidad en el siglo XVIII español e italiano / Ozio e oziosità nel Settecento italiano e spagnolo. Frankfurt am Main: Klostermann, 2017. 
extensiones y límites del espacio público y privado, la repartición de roles sociales o la creación de un nuevo sistema de valores, sin olvidar la legitimidad de ciertas estéticas o géneros dramáticos.

En el presente artículo me propongo, pues, aportar algunas observaciones acerca de las preguntas esenciales: ¿̇cuáles son la importancia y el significado del ocio y de la ociosidad en el discurso sobre el teatro?, ¿hasta qué punto y bajo qué perspectiva el ocio y la ociosidad se ven representados en la escena misma? y ¿cómo se plantea, en este caso, la relación entre discurso y representación? Para contestar a estas preguntas se efectuará en primer lugar un breve recorrido desde la controversia sobre la licitud del teatro hasta la Memoria para el arreglo de la policía de los espectáculos y diversiones públicas y sobre su origen en España (1790/1796) de Gaspar Melchor de Jovellanos (1744-1811), un tratado que respecto a la complejidad de su planteamiento solo se puede comparar con la Lettre à d'Alembert sur les spectacles (1758) de Jean-Jacques Rousseau. En la segunda parte del artículo se abordará la cuestión de la representación concreta y de la valoración respectiva del ocio y de la ociosidad en la comedia neoclásica, el drama sentimental y, más brevemente, en el sainete a partir de varios ejemplos seleccionados.

\section{OCIO Y OCIOSIDAD EN EL DISCURSO SOBRE EL TEATRO}

Reflexionar sobre la importancia de los conceptos del ocio y de la ociosidad en el discurso sobre el teatro dieciochesco significa entrar en un campo bastante amplio y complejo. Me limitaré, por lo tanto, en este contexto a evocar algunos hechos básicos y a trazar unas líneas generales. En su extensa Bibliografía de las controversias sobre la licitud del teatro en España de 1904, Emilio Cotarelo y Mori enumera y comenta solo para el siglo dieciocho setenta y siete tratados a este respecto, en su gran mayoría de una orientación crítica hacia el teatro ${ }^{8}$. Veamos, pues, en primer lugar las posiciones maximalistas. Cuentan entre ellas, por un lado, todos los que abogan por permitir que el teatro tradicional y popular se desarrolle en toda libertad sujeto solo a la demanda y al gusto del público y, por otro lado, los que exigen o, por lo menos, consideran en serio que el teatro se elimine completamente del espacio público.

Si bien es verdad que «[1]os teóricos de los gustos populares en el siglo XVIII son menos numerosos que sus críticos»", como lo destaca Emilio Palacios Fernández, no lo es menos que existen documentos muy llamativos al respecto. El más

8. Véanse la síntesis y la lista correspondiente en COTARELO y MORI, Emilio. Bibliografía de las controversias sobre la licitud del teatro en España. Madrid: Revista de Archivos, Bibliotecas y Museos, 1904 , pp. 28-35 y 614-616.

9. Palacios Fernández, Emilio. "Teatro». En Aguilar Piñal, Francisco (ed.). Historia literaria de España en el siglo XVIII. Madrid: Trotta, 1996, pp. 135-233; p. 139. 
representativo es probablemente el Discurso crítico sobre el origen, calidad y estado presente de las comedias de España publicado en 1750 por Ignacio de Loyola Oyanguren, marqués de la Olmeda, bajo el seudónimo Tomás Erauso y Zavaleta. En esta réplica que está dirigida contra el neoclásico Blas Antonio de Nasarre Erauso y que se remite al Arte nuevo de hacer comedias (1609) de Lope de Vega y defiende la representación de las antiguas comedias de Lope y de Calderón, declara rotundamente que la finalidad suprema del teatro es el entretenimiento del público: "Las Comedias son recreo, son diversión, y empleo del ocio: por cuyas causas, el gusto es el más fuerte Legislador suyo» ${ }^{10}$.

A esta posición permisiva se oponen las actitudes represivas que aspiran a cerrar los teatros y mantener alejado al pueblo de los espectáculos, porque se los considera una ocupación indecente y peligrosa para el orden público. Muchos representantes de la Iglesia, cuyos argumentos poco originales se fundan principalmente en los escritos de los Padres de la Iglesia, y -hay que mencionarlo- no pocos reformadores ilustrados están de acuerdo con esta actitud. Si tomamos solamente el ejemplo de Jovellanos podemos observar que, aunque no apruebe "los ataques con que han combatido la escena moderna muchos de nuestros teólogos ${ }^{11}$, profesa, sin embargo, respecto al teatro de su tiempo que le parece profundamente corrupto y depravado a nivel moral: "Un teatro tal es una peste pública, y el gobierno no tiene más alternativa que reformarlo o proscribirlo para siempre» ${ }^{12}$. Y en lo tocante a los entremeses, sainetes y tonadillas, opina: "Acaso fuera mejor desterrar enteramente de nuestra escena un género expuesto de suyo a la corrupción y a la bajeza, e incapaz de instruir y elevar el ánimo de los

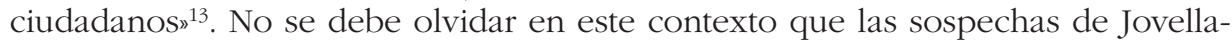
nos contra el teatro como ocio ilícito tienen unos ilustres predecesores en filósofos como Rousseau o el mismo Platón. Y recordemos también que incluso a la práctica teatral de los neoclásicos se le ha reprochado a menudo que es demasiado seca y doctrinal para cumplir con los requisitos básicos de la teatralidad o del deleite indispensable para que el teatro aún pueda pasar por ocio ${ }^{14}$.

Sin embargo, además de estas posiciones maximalistas existen también actitudes moderadas, inspiradas por el precepto horaciano y aristotélico de instruir

10. ERAuso y Zavaleta, Tomás. Discurso crítico sobre el origen, calidad y estado presente de las comedias de España. Madrid: Imprenta de Juan de Zúñiga, 1750, p. 56.

11. Jovellanos, Gaspar Melchor de. «Memoria sobre las diversiones públicas». En JovelLANOS, Gaspar Melchor de. Espectáculos y diversiones públicas. Informe sobre la Ley Agraria. Editado por Guillermo Carnero. Madrid: Cátedra, 1998, pp. 111-222; p. 175.

12. Ibidem, p. 178.

13. Ibidem, p. 203.

14. Este aspecto se trata también en TschilschKe, Christian von. "María Rosa Gálvez’ neoklassizistische Komödie La familia a la moda (1805): Paradigma für eine neue Ökonomie des Theaters?». En SCHUChardT, Beatrice y Urban, Urs (eds.). Handel, Handlung, Verhandlung. Theater und Ökonomie in der Früben Neuzeit in Spanien. Bielefeld: Transcript, 2014, pp. 283-303; p. 296. 
deleitando, que conceden más espacio al entretenimiento sometiéndolo a fines utilitarios e instructivos. De este modo, se funcionaliza el ocio para combatir la ociosidad. El representante más notable de esta tendencia es seguramente Ignacio de Luzán. En el décimo capítulo del tercer libro de su Poética (1737/1789), «De las costumbres", constata lo siguiente:

Es cierto que el pueblo, particularmente en las grandes ciudades, debe tener alguna pública diversión con que entretener y engañar el ocio, semilla y causa de muchos vicios y desórdenes; es cierto también que entre todos los divertimientos públicos el más bien recibido comúnmente, y el de mayor gusto, es el de las comedias; con que, por esta parte, se logra con ellas, mejor que con cualquier otro medio, el tener por algunas horas ocupada y embelesada la ociosidad del pueblo ${ }^{15}$.

De paso cabe señalar que tal concepto se corresponde perfectamente con la mentalidad de un monarca como Carlos III a quien Antonio Domínguez Ortiz caracteriza de la manera siguiente:

Temeroso de la neurastenia y la depresión que habían hecho estragos en otros miembros de su familia había adoptado como norma no estar nunca ocioso; y como no era amante de la música, el teatro y muy poco de los juegos de azar (podríamos añadir: ni de la lectura) la caza resultaba ser la ocupación más adecuada y más higiénica ${ }^{16}$.

Entre los que, tal como Luzán, defienden posiciones mesuradas se encuentran también aquellos que aceptan de mala gana la inmoralidad de los espectáculos populares por su función compensatoria entendiéndoles en sentido aristotélico como una catarsis de las malas inclinaciones. Por ese motivo, según el testimonio ofrecido por el presbítero Nicolás Blanco en su tratado Examen teologico-moral sobre los teatros actuales de España (1766) y resumido como sigue por Francisco Sánchez-Blanco, "algunos eruditos defendían las comedias con todos sus defectos y obscenidades para prevenir males mayores: si no se permitía a los hombres divertirse y matar el tiempo con amores imaginados, éstos se dedicarían de verdad a seducir mujeres ${ }^{17}$.

Otros representantes del bando ilustrado y reformista adoptan aún actitudes más casuísticas y diferenciadas según las ocasiones y los públicos respectivos. Así, por ejemplo, es cierto que el conde de Aranda en su función de presidente del Consejo de Castilla practica una política cultural que suprime los autos sacramentales y promueve la reforma del teatro en el sentido neoclásico, pero entre 1767 y 1773 «también organiza bailes de disfraces que no tienen ninguna finalidad

15. LuZÁn, Ignacio de. La poética o reglas de la poesía en general, y de sus principales especies. Editado por Russell P. Sebold. Madrid: Cátedra, 2008, pp. 564-565. p. 49.

16. Domínguez Ortiz, Antonio. Carlos III y la España de la Ilustración. Madrid: Alianza, 1988,

17. SÁnchez-Blanco, Francisco. El Absolutismo y las Luces..., op. cit., p. 150. 
didáctica» ${ }^{18}$. Otro caso bien conocido es el de Nicolás Fernández de Moratín, quien en sus Desengaños al teatro español (1762/1763) arremete contra el teatro barroco, el sainete y los autos sacramentales mientras que defiende en su Carta histórica sobre el origen y progresos de las fiestas de toros en España (1776) la corrida como diversión legítima afirmando el juicio de la reina Amalia que al verla había opinado: "No era barbaridad, como la habían informado, sino diversión donde brilla el valor y la destreza» ${ }^{19}$.

Resumiendo lo que hemos expuesto hasta ahora, podemos constatar que en el discurso sobre el teatro, por lo general, el tema del ocio solo se enfoca indirectamente, a través de sus contenidos y las actitudes del ser humano ante su tiempo libre. Se tematiza, asimismo, mediante el debate poetológico y político en torno al teatro, el papel de las instancias que deciden sobre dichos contenidos y actitudes; de igual modo, en particular se plantea la cuestión de hasta qué punto el Estado y la Iglesia deben ejercer influencia sobre la manera en que sus súbditos utilizan el tiempo del que disponen.

Si hay un texto que va más allá de este enfoque relativamente limitado es la ya mencionada Memoria sobre los espectáculos y diversiones públicas de Jovellanos presentada por primera vez en 1790 por encargo del Consejo de Castilla y la Academia de la Historia en 1786, reelaborada en 1796 y finalmente publicada en 1812. Ese texto destaca por cuatro motivos: trata el teatro precisamente en relación con su función de diversión pública, es decir, como un efecto específico del ocio, lo incluye con otras diversiones públicas en un vasto panorama histórico, se acerca a este panorama, al menos en la primera parte, de una manera descriptiva, no normativa, y trata de esbozar, en la segunda parte, la parte normativa de su tratado, una policía del ocio, o sea, del tiempo libre en general. Jovellanos crea, de este modo, por primera vez una verdadera historia cultural de las diversiones públicas en España desde los romanos hasta la actualidad de su tiempo, haciendo mención, entre otros, de la caza, de los torneos, de los toros, de las fiestas palaciegas, de las romerías, de los juegos y, por supuesto, del teatro. Este trabajo historiográfico se realiza, como resalta su autor, «a los ojos de la moderna cultura ${ }^{20}$. Por tanto, prescinde conscientemente de toda nostalgia y resulta del afán genuinamente ilustrador de dar a conocer a la nación su propia historia.

La segunda parte de su memoria, empero, en la que Jovellanos habla como político y descubre el teatro como -en sus propias palabras- "objeto de la legislación" ${ }^{21}$, también es novedosa tal como lo reivindica él mismo: "La escena en los Estados modernos ha seguido naturalmente el causal progreso de su

18. Ibidem, p. 151.

19. FERnÁndez de Moratín, Nicolás. "Carta histórica sobre el origen y progresos de las fiestas de toros en España». En Obras de Don Nicolás y de Don Leandro Fernández de Moratín. Madrid: Atlas, 1944, pp. 141-144; p. 144.

20. Jovellanos, Gaspar Melchor de. "Memoria... ", op. cit., p. 149.

21. Ibidem, pp. 198-199. 
ilustración y debídose al ingenio de algunos pocos literatos, sin que la autoridad pública haya concurrido a ella más que ocasionalmente» ${ }^{22}$. Así pues, Jovellanos parte de una constatación menos antropológica que política cuando afirma que, para ser felices, los pueblos necesitan diversiones. A continuación introduce una distinción social, fundamental para su argumentación, a saber: la de «dos clases, una que trabaja y otra que huelga». Posteriormente, explica estas clases de la siguiente manera: "Comprenderé en la primera todas las profesiones que subsisten del producto de su trabajo diario; y en la segunda, las que viven de sus rentas o fondos seguros ${ }^{23}$. En realidad, esta distinción no es tan clara como parece, porque no encaja directamente con la estructura estamental. Por ejemplo, pasa por alto completamente a las nuevas clases altas de la naciente burguesía y de lo que Leandro Fernández de Moratín iba a llamar en el "Discurso preliminar" de sus Obras dramáticas y líricas, publicado en 1825, la "clase media»"

A "la gente pobre que vive de su trabajo, para la cual el tiempo es dinero»", como dice el famoso razonamiento a la vez economista y moralista, liberal y paternalista de Jovellanos, si bien se le concede el derecho al tiempo libre y a disponer libremente de ello, fuera del control del Estado, se le niega por otro lado o, al menos, se desaprueba que frecuente el teatro:

Este pueblo necesita diversiones, pero no espectáculos. No ha menester que el gobierno lo divierta, pero sí que le deje divertirse. En los pocos días, en las breves horas que puede destinar a su solaz y recreo, él buscará, él inventará sus entretenimientos. Basta que se le dé libertad y protección para disfrutarlos. Un día de fiesta claro y sereno en que pueda libremente pasear, correr, tirar a la barra, jugar a la pelota, al tejuelo, a los bolos, merendar, beber, bailar y triscar por el campo, llenará todos sus deseos y le ofrecerá la diversión y el placer más cumplidos ${ }^{26}$.

Con todo, Jovellanos está absolutamente consciente del carácter utópico de esta visión y advierte que la realidad del pueblo, en la que reinan «una perezosa inacción, un triste silencio ${ }^{27}$, es otra:

Si algunas personas salen de sus casas, no parece sino que el tedio y la ociosidad las echan de ellas y las arrastran al ejido, al humilladero, a la plaza o al pórtico de la

22. Ibidem, p. 199.

23. Ibidem, p. 183.

24. FERnÁNDEZ de Moratín, Leandro. "Discurso preliminar». En Obras..., op. cit., pp. 307-325; p. 321. Sin embargo, no debe pasar inadvertido que incluso Jovellanos admite: «Es verdad que habrá todavía muchas personas en una situación media, pero siempre pertenecerán a esta o aquella clase según que su situación incline más o menos a la aplicación o a la ociosidad» (JovelLANos, Gaspar Melchor de. "Memoria... ", op. cit., p. 183).

25. Ibidem, p. 214.

26. Ibidem, p. 183. En este párrafo se reflejan directamente las ideas de Rousseau, como señala también CARNERO, Guillermo. "Introducción». En JOvEllanos, Gaspar Melchor de. Espectáculos y diversiones..., op. cit., pp. 11-109; p. 67.

27. Jovellanos, Gaspar Melchor de. "Memoria... ", op. cit., p. 184. 
iglesia, donde, embozados en sus capas o al arrimo de alguna esquina, o sentados o vagando acá y acullá sin objeto ni propósito determinado, pasan tristemente las horas y las tardes enteras sin espaciarse ni divertirse ${ }^{28}$.

Mientras que, en la opinión de Jovellanos, la parte activa de la población debe ser alejada del teatro, para "la clase rica y propietaria»" ${ }^{29}$, por su parte comúnmente entregada al ocio, los espectáculos son indispensables justamente como «recurso para la ociosidad ${ }^{30}$. Si ya ha de ser perdida esta clase para el trabajo, al menos debería instruirse en el teatro.

En la Memoria de Jovellanos hay diversos puntos que llaman particularmente la atención en cuanto al tema del ocio y de la ociosidad. Como no es de extrañar para el texto de un reformador ilustrado sobre las diversiones públicas, la esfera del ocio siempre queda relacionada con el mundo del trabajo y con las ideas de la utilidad y del bien común. Lo que más sorprende, sin embargo, es la distancia que le separa del modelo ilustrado descrito, por ejemplo, por Jürgen Habermas en su libro Historia y crítica de la opinión pública (1962), modelo según el cual «[e]1 "pueblo" es elevado a cultura, no la cultura degradada a masa»31.

Si bien es verdad que, quitando al vulgo el placer de los espectáculos, Jovellanos rehúye la idea de una cultura masiva de consumo, también niega al mismo tiempo la posibilidad de educar al vulgo a través del teatro relegándole, a la manera algo utópica de Rousseau, a los ocios activos y espontáneos que, en su opinión, enriquecen la cultura popular. Quizás la actitud defensiva que muestra Jovellanos en este contexto se explique también por el efecto traumático que tuvo la experiencia de la Revolución francesa sobre los ilustrados españoles.

\section{OCIO Y OCIOSIDAD EN EL TEATRO}

Después de haber considerado, al menos sumariamente, la presencia implícita y explícita del ocio y de la ociosidad en el debate sobre el teatro y antes de abordar el aspecto de su representación en el teatro dieciochesco, parece indicado hacer una observación previa. Además de ser objeto de algunas restricciones históricamente concretas de índole moral e ideológica, como la necesidad de servir a la "utilidad pública» y de contribuir al "bien general», ya el teatro en sí, en su calidad primaria de género y medio, sufre algunas restricciones en cuanto a la posibilidad de representar el ocio y la ociosidad como inacción, recogimiento, silencio, retiro o vida contemplativa dado que se basa principalmente en la acción

28. Ibidem.

29. Ibidem, p. 202.

30. Ibidem, p. 214.

31. Habermas, Jürgen. Historia y crítica de la opinión pública. Traducido por Antonio Doménech, con la colaboración de Rafael Grasa. 4. ${ }^{a}$ ed. Barcelona: Ediciones G. Gili, 1994, p. 194. 
física y verbal. Por otro lado, empero, precisamente esto permite también suponer que el teatro tiene un potencial específico para hacer resaltar todo tipo de ocio o de ociosidad.

Con esta perspectiva y bajo estos criterios discursivos, genéricos y mediáticos, vamos ahora a examinar, de manera bastante breve y fragmentaria, por cierto, algunos ejemplos del ocio y de la ociosidad que se encuentran en la comedia de tendencia neoclásica. Para empezar, echemos un vistazo a la comedia La familia a la moda, de María Rosa Gálvez, estrenada por primera vez en 1805 y compuesta al estilo de las comedias de Leandro Fernández de Moratín y Tomás de Iriarte. En la escena XI del segundo acto de La familia a la moda se nos confronta con una situación en varios aspectos emblemática e ideológicamente representativa de la comedia neoclásica. Vemos al padre de familia Don Canuto de Pimpleas sentado a una mesa, preparando a disgusto una lista con todas sus deudas de juego, tarea que le ha impuesto su hermana, la viuda Doña Guiomar, que es la única que tiene la autoridad y los recursos necesarios para salvar la familia arruinada de la miseria. Al lado de su padre el hijo Faustino, por carecer de pareja, está repasando sus lecciones de baile con una silla como si no pasara nada. En este cuadro Gálvez logra visualizar simultáneamente el vicio de la ociosidad -la falta de entrega al trabajo y la dedicación a pasatiempos necios y perniciosos-, las graves consecuencias de este comportamiento - la ruina económica y el fracaso de la familia- y los remedios indicados por la nueva moral burguesa propagada por Doña Guiomar -trabajo, industria, modestia, economía y disciplina-.

A los tópicos del padre apasionado por el juego y de la juventud desorientada y ociosa aún se añade el motivo corriente de la petimetra, encarnada por Madama de Pimpleas, que derrocha el dinero en viajes a Francia, moda, artículos de lujo y bailes. Gálvez no deja lugar a dudas de que esta actitud de ociosidad y consumo ostensible está motivada por el deseo de comportarse como los nobles y codearse con ellos.

Como era de esperar, la dicotomía entre las alabanzas del trabajo útil de las clases productivas y la censura a la ociosidad de la nobleza constituye el eje axiológico de base según el cual se plantea el problema del ocio y de la ociosidad en la comedia. Por eso, el inventario de motivos reunidos en La familia a la moda -«[1]a compone un jugador / con una esposa insolente / y un muchacho impertinente ${ }^{32}$, como deplora Doña Guiomar- también se encuentra, con los matices correspondientes, en un gran número de otras comedias, donde sirve para caracterizar a labradores, artesanos y los representantes de la nueva élite funcional. Citemos algunos ejemplos. Para descalificarle, en el drama sentimental El delincuente honrado (1773) de Jovellanos, se retrata al Marqués de Montilla,

32. GÁlvez, María Rosa de. "La familia a la moda». En GÁlvez, María Rosa de. Safo. Zinda. La familia a la moda. Editado por Fernando Doménech. Madrid: Publicaciones de la Asociación de Directores de Escena de España, 1995, pp. 139-257; p. 230. 
el contrincante del protagonista Torcuato, como hombre "[e]ntregado a todos los vicios, y siempre enredado con tahúres [jugadores] y mujercillas, después de haber disipado el caudal de su esposa "33 $^{33}$.

Recurriendo al tradicional desprecio de la corte, en la comedia El barón (1803), de Leandro Fernández de Moratín, el protagonista Don Pedro reprocha a su hermana, la Tía Mónica, una labradora acomodada, el hecho de que se muestre sensible a las lisonjas del falso Barón de Montepino con las siguientes palabras: «¿No es cierto que allá en tu mente / el plan de vida repasas / que has de tener? Coches, modas, / brillantes, sedas y holandas, [...] / Baile, academias, teatros, [...] / Llamar cultura a la infame / Depravación cortesana, / Bestia a todo hombre de

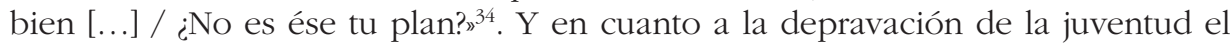
mismo Don Pedro retoma la oposición igualmente tradicional entre campo (Illescas, en este caso) y ciudad (Madrid): "Es cierto / que no hay aquí -y es desgracia- / una juventud de alcorza, / corrompida y perfumada, / cigarrera, petulante, / ociosa, habladora y fatua, / como la que he visto yo / ir bailando contradanzas, / allá en la Puerta del Sol»’35.

En la comedia artesanal Los menestrales (1784), de Cándido María Trigueros, que aboga por la revalorización y el reconocimiento social del trabajo, se presenta, en cambio, a un noble, Don Juan, para quien "no hay incompatibilidad entre trabajo manual y nobleza»" ${ }^{36}$, al contrario: "El ser inútil, ser ocioso y malo / se opone a la nobleza, no el oficio: / noble será, si es bueno, el artesano» ${ }^{37}$. Mas, en $E l$ delincuente bonrado, publicado unos diez años antes, la nueva ética ilustrada y burguesa del trabajo ha sido ya tan interiorizada por los personajes que es menester aconsejarles que descansen y se cuiden un poco. Así, Don Simón, el padre de Torcuato, dice con un tono admirativo con respecto a Don Justo, el suegro de Torcuato, que incorpora el modelo de un juez ilustrado: "El hombre no sosiega. Con el bocado en la boca vuelve a su trabajo ${ }^{38}$. Por ese motivo, no tarda en dirigirle las palabras siguientes cuando le encuentra: «Señor, vos trabajáis mucho y a malas horas; cuidad más de vuestro descanso, que al cabo de la jornada sale más bien librado el que se incomoda menos ${ }^{39}$. De hecho, El delincuente honrado es una de las pocas piezas en las que se da una imagen positiva del ocio, debido, sin duda, a la influencia de la comedia burguesa de Diderot y su específico realismo de la vida privada. De este modo se precisa, en las acotaciones al primer y al segundo

33. Jovellanos, Gaspar Melchor de. "El delincuente honrado». En JovelLanos, Gaspar Melchor de. Poesía, teatro y prosa. Editado por John H. R. Polt. Madrid: Taurus, 1993, pp. 223-288; p. 231.

34. FERnÁNDEZ de Moratín, Leandro. "El barón». En Obras..., op. cit., pp. 373-391; p. 386.

35. Ibidem, p. 383.

36. Pérez Magallón, Jesús. El teatro neoclásico. Madrid: Ediciones del Laberinto, 2001, p. 277.

37. Trigueros, Cándido María. Los menestrales. Editado, introducido y anotado por Francisco Aguilar Piñal. Sevilla: Universidad de Sevilla, 1997, p. 186.

38. Jovellanos, Gaspar Melchor de. "El delincuente...", op. cit., p. 255.

39. Ibidem. 
acto, que Torcuato «toma un libro, empieza a leer» ${ }^{40}$ y que su esposa Laura está "haciendo labor" ${ }^{41}$.

Parece que la representación positiva de diversiones públicas en las comedias neoclásicas también es bastante escasa. No obstante, la comedia ya mencionada de Trigueros, Los menestrales, constituye un buen ejemplo al combinar el elogio del trabajo con la puesta en escena de una fiesta espléndida en «un magnífico jardín en Chamartín " ${ }^{42}$ cerca de Madrid, "adornado e iluminado» ${ }^{43}$, en el que se presentan, acompañados de orquesta y coro, canciones, bailes de moda como el "fandango" ${ }^{44}$ y la "Seguidilla» ${ }^{45}$ y máscaras. Los menestrales rebosan por consiguiente de esta "teatralidad" cuya falta se ha deplorado tanto en la comedia neoclásica, incluso en el caso de La familia a la moda de Rosa María Gálvez, que acabamos de evocar ${ }^{46}$.

Pero esto no cambia en nada el hecho de que en Los menestrales la representación de las diversiones populares y campestres esté sometida, y aún tanto más, a unos fines ideológicos bien reconocibles: por un lado, la pieza fue concebida como homenaje explícito al monarca Carlos III y su política cultural ${ }^{47}$, y en lo relativo al argumento se trata, por otro lado, una vez más de sancionar a un falso barón. Rafa, como se llama el estafador, es un antiguo zapatero que se delata, involuntariamente, justamente cuando manifiesta su gusto por tocar la guitarra y entonar "una cantinela»" y una popular "tirana rusa" ${ }^{49}$. René Andioc comenta esta

40. Ibidem, p. 225.

41. Ibidem. p. 240. En ambos casos, la manera como se abre la escena al inicio de los actos recuerda muy exactamente a las primeras escenas de las piezas de Diderot Le fils naturel (1757) y Le père de famille (1758) que, además, también comienzan con "pantomimas» de los personajes aun antes de que hablen (y que, por lo demás, cada vez tienen un juego trictrac a su alcance).

42. Trigueros, Cándido María. Los menestrales, op. cit., p. 91.

43. Ibidem, p. 159.

44. Ibidem, p. 179.

45. Ibidem, p. 182.

46. Véase con respecto a La familia a la moda DOMÉNECH, Fernando. "Estudio preliminar". En Gálvez, María Rosa de. Safo..., op. cit., pp. 9-47; p. 41: "[...] el mayor reproche que se le puede hacer es su falta de lances cómicos, su sencillez que llega a la monotonía. La autora ha planteado una situación, ha dibujado a sus personajes y los ha dejado llegar a la conclusión más esperada sin ningún tropiezo, sin ningún efecto de teatro. Que María Rosa Gálvez sabía inventar incidentes, dar vuelta a las situaciones y crear expectativas en el espectador es algo que se puede comprobar en otras obras suyas. Si no lo hace en ésta es con un propósito deliberado. Sin duda quiso hacer una "comedia seria", un ejemplo moral y cívico sin condiciones a la galería, y escribió una pieza lineal, sin incidentes, y por ello excesivamente rígida. Es una comedia a la que le sobra severidad y le falta alegría. Una lección demasiado seca de ideología ilustrada».

47. Sobre las circunstancias concretas de su creación informa AGUILAR PIÑAL, Francisco. "Introducción». En Trigueros, Cándido María. Los menestrales, op. cit., pp. 9-63. La comedia fue redactada para la conmemoración festiva del tratado de paz firmado con Inglaterra en 1783 y el nacimiento de infantes gemelos en el mismo año.

48. Trigueros, Cándido María. Los menestrales, op. cit., p. 119.

49. Ibidem, p. 123. 
escena así: «Se nos sugiere que por ley natural el plebeyo no puede desmentir su condición, y que por consiguiente no debe abandonar el trabajo "útil" por correr tras una ilusión perjudicial para la economía del país ${ }^{50}$. Desde nuestra perspectiva, centrada en la representación del ocio y de la ociosidad, podemos añadir que la interpretación de Andioc -ciertamente acertada- presupone inevitablemente la existencia de una distinción preestablecida que identifica una jerarquía social bastante rígida con una visión de las diversiones públicas no menos jerarquizada -semejante a las ideas que Jovellanos desarrolla en su Memoria- en el sentido de que "por sus diversiones los conoceréis».

Esto resulta todavía más cierto en el caso del teatro popular y las formas breves como el sainete. Aunque en la realidad a veces se distingue menos de la comedia de lo que los teóricos habían afirmado ${ }^{51}$, ofrece, no obstante, un abanico mucho más amplio de diversiones populares y cotidianas, de las fiestas, las danzas y la música. Ramón de la Cruz, por ejemplo, integra a menudo fandangos, seguidillas y boleros a sus obras -a los deleites del beber y comer, pasando por los paseos, conversaciones, etcétera-. Al representar los ocios desde un punto de vista en suma menos normativo y censurador que la comedia, hasta que fue considerado francamente de "documental» o incluso "etnológico» ${ }^{52}$, el sainete más que nada evidencia la convicción ya invocada por Jovellanos en su Memoria, pero con otros motivos y conclusiones, de que el ocio forma parte elemental de la existencia humana.

\section{CONCLUSIÓN: EL BUEN USO DEL OCIO}

Pese al número necesariamente limitado de ejemplos a los que hemos pasado revista, ha quedado bien claro que el ocio y la ociosidad constituyen un tema recurrente en la discusión sobre el teatro y las obras teatrales mismas aunque se plantea a menudo implícitamente o se enfoca indirectamente mediante sus efectos y manifestaciones diversas. A nivel axiológico se nota una oposición bastante marcada entre el rechazo omnipresente de la ociosidad tanto de la clase nobilitaria como "del pueblo que trabaja "53 (o debería trabajar) y, más escasamente, la defensa del ocio como recreo debido y merecido de la nueva clase media productiva y

50. ANDIOC, René. «El teatro de Leandro Fernández de Moratín». En CARNERO, Guillermo (ed.). Historia de la literatura española. Siglo XVIII, tomo II. Madrid: Espasa-Calpe, 1995, pp. 550-584; p. 570.

51. Véase acerca de este punto Álvarez BARrientos, Joaquín. «Introducción». En FernándeZ DE Moratín, Leandro. La comedia nueva o el café. Editado, introducido y anotado por Joaquín Álvarez Barrientos. Madrid: Biblioteca Nueva, 2000, pp. 7-50; p. 32.

52. Esto lo han constatado, por ejemplo, Emilio Cotarelo y Mori, Arthur Hamilton o Charles E. Kany (véase Lafarga, Francisco. «Introducción». En CruZ, Ramón de la. Sainetes. Editado por Francisco Lafarga. 2. ${ }^{\text {e }}$ ed. Madrid: Ediciones Cátedra, 2003, pp. 9-53; p. 25).

53. Jovellanos, Gaspar Melchor de. "Memoria...", op. cit., p. 183. 
del vulgo entregado a las diversiones tradicionales y actuales al aire libre que le corresponden.

Si bien es verdad que las recomendaciones de cómo se debería disfrutar del tiempo libre difieren según el origen social de los desocupados, coinciden, sin embargo, en el hecho de que nunca preconizan la inacción total o la omisión de toda actividad, ajenas del valor supremo de la "utilidad pública», sino que siempre se presentan como «diversión» dinámica y activa. Con esto, precisamente, las nuevas políticas de las diversiones públicas coinciden con la determinación esencial del teatro como género y medio que es acción. En cuanto al nivel estilístico de las piezas teatrales, alterna el registro de lo cómico y de la sátira moral con la seriedad que requiere el realismo escénico de la estética e ideología de los ilustrados. De este modo, mediante las teorías y prácticas del teatro operan durante la segunda mitad del siglo XVIII dos procesos que no son de ninguna manera contradictorios: la diferenciación social del ocio y el control unificador del mismo.

\section{5, BiBLIOGRAFÍA}

Aguilar Piñal, Francisco. «Introducción». En Trigueros, Cándido María. Los menestrales. Editado, introducido y anotado por Francisco Aguilar Piñal. Sevilla: Universidad de Sevilla, 1997, pp. 9-63.

Álvarez Barrientos, Joaquín. «Introducción». En Fernández de Moratín, Leandro. La comedia nueva o el café. Editado, introducido y anotado por Joaquín Álvarez Barrientos. Madrid: Biblioteca Nueva, 2000, pp. 7-50.

ANDIOC, René. Teatro y Sociedad en el Madrid del siglo XVIII. 2. ${ }^{a}$ ed. corregida y aumentada. Madrid: Castalia, 1987.

ANDIOC, René. «El teatro de Leandro Fernández de Moratín». En CARNERo, Guillermo (ed.). Historia de la literatura española. Siglo XVIII, tomo II. Madrid: Espasa-Calpe, 1995, pp. 550-584.

CARnero, Guillermo (ed.). Historia de la literatura española. Siglo XVIII, tomo II. Madrid: Espasa-Calpe, 1995.

CARNero, Guillermo. "Introducción». En Jovellanos, Gaspar Melchor de. Espectáculos y diversiones públicas. Informe sobre la Ley Agraria. Editado por Guillermo Carnero. Madrid: Cátedra, 1998, pp. 11-109.

Cook, John A. Neo-classic Drama in Spain. Theory and Practice. Dallas: Southern Methodist University Press, 1959.

COTARELO y MORI, Emilio. Bibliografía de las controversias sobre la licitud del teatro en España. Madrid: Revista de Archivos, Bibliotecas y Museos, 1904.

Diccionario de Autoridades, tomo V, 1737. http://web.frl.es/DA.html.

Diccionario de la Real Academia Española. 22. ${ }^{a}$ ed., 2012. http://lema.rae.es/drae/.

DOMÉNECH, Fernando. «Estudio preliminar». En Gálvez, María Rosa de. Safo. Zinda. La familia a la moda. Editado por Fernando Doménech. Madrid: Publicaciones de la Asociación de Directores de Escena de España, 1995, pp. 9-47.

Domínguez Ortiz, Antonio. «La batalla del teatro en el reinado de Carlos III (I)». Anales de Literatura Española, 1983, 2, pp. 177-196. 
ASPECTOS DEL OCIO Y DE LA OCIOSIDAD EN EL TEATRO Y EN EL DISCURSO SOBRE EL TEATRO...

Domínguez Ortiz, Antonio. "La batalla del teatro en el reinado de Carlos III (II)». Anales de Literatura Española, 1984, 3, pp. 207-234.

Domínguez OrTiz, Antonio. Carlos III y la España de la Ilustración. Madrid: Alianza, 1988.

ERauso y Zavaleta, Tomás. Discurso crítico sobre el origen, calidad y estado presente de las comedias de España. Madrid: Imprenta de Juan de Zúñiga, 1750.

FAJEN, Robert y Gelz, Andreas (eds.). Ocio y ociosidad en el siglo XVIII español e italiano / Ozio e oziosità nel Settecento italiano e spagnolo. Frankfurt am Main: Klostermann, 2017.

FERNÁNDEZ DE MORATín, Leandro. «Discurso preliminar». En Obras de Don Nicolás y de Don Leandro Fernández de Moratín. Madrid: Atlas, 1944a, pp. 307-325.

FERnÁNDEZ De Moratín, Leandro. "El barón". En Obras de Don Nicolás y de Don Leandro Fernández de Moratín. Madrid: Atlas, 1944b, pp. 373-391.

FERNÁNDEZ DE MORATín, Nicolás. «Carta histórica sobre el origen y progresos de las fiestas de toros en España». En Obras de Don Nicolás y de Don Leandro Fernández de Moratín. Madrid: Atlas, 1944c, pp. 141-144.

GÁlvez, María Rosa de. "La familia a la moda» En Gálvez, María Rosa de. Safo. Zinda. La familia a la moda. Editado por Fernando Doménech. Madrid: Publicaciones de la Asociación de Directores de Escena de España, 1995, pp. 139-257.

GODZICH, Wlad y SPADACCINI, Nicholas. "Introduction. From Discourse to Institution». En GODZICH, Wlad y SPADACCINI, Nicholas (eds.). The Institutionalization of Literature in Spain. Minneapolis: The Prisma Institute, 1987, pp. 9-38.

HABERMAS, Jürgen. Historia y crítica de la opinión pública. Traducido por Antonio Doménech, con la colaboración de Rafael Grasa. 4. ${ }^{a}$ ed. Barcelona: Ediciones G. Gili, 1994.

Jovellanos, Gaspar Melchor de. «El delincuente honrado». En Jovellanos, Gaspar Melchor de. Poesía, teatro y prosa. Editado por John H. R. Polt. Madrid: Taurus, 1993, pp. 223-288.

Jovellanos, Gaspar Melchor de. «Memoria sobre las diversiones públicas». En JovelLanos, Gaspar Melchor de. Espectáculos y diversiones públicas. Informe sobre la Ley Agraria. Editado por Guillermo Carnero. Madrid: Cátedra, 1998.

Lafarga, Francisco. «Introducción». En Cruz, Ramón de la. Sainetes. Editado por Francisco Lafarga. 2. ${ }^{a}$ ed. Madrid: Ediciones Cátedra, 2003, pp. 9-53.

LuZÁn, Ignacio de. La poética o reglas de la poesía en general, y de sus principales especies. Editado por Russell P. Sebold. Madrid: Cátedra, 2008.

Maravall, José Antonio. "La función educadora del teatro en el siglo de la Ilustración» (1982). En Maravall, José Antonio. Estudios de la historia del pensamiento español (siglo XVIII). Editado por María del Carmen Iglesias. Madrid: Mondadori, 1991a, pp. 382-406.

Maravall, José Antonio. "Política directiva en el teatro ilustrado» (1988). En Maravall, José Antonio. Estudios de la historia del pensamiento español (siglo XVIII). Editado por María del Carmen Iglesias. Madrid: Mondadori, 1991b, pp. 524-536.

Palacios Fernández, Emilio. «Teatro». En Aguilar Piñal, Francisco (ed.). Historia literaria de España en el siglo XVIII. Madrid: Trotta, 1996.

Pérez Magallón, Jesús. El teatro neoclásico. Madrid: Ediciones del Laberinto, 2001.

Rubio Jiménez, Jesús. El conde de Aranda y el teatro. Zaragoza: Caja de Ahorros y Monte de Piedad de Zaragoza, Aragón y Rioja, 1998.

SÁnCHEZ-Blanco, Francisco. El Absolutismo y las Luces en el reinado de Carlos III. Madrid: Marcial Pons, 2002. 
Trigueros, Cándido María. Los menestrales. Editado, introducido y anotado por Francisco Aguilar Piñal. Sevilla: Universidad de Sevilla, 1997.

TschilschKe, Christian von. "María Rosa Gálvez' neoklassizistische Komödie La familia a la moda (1805): Paradigma für eine neue Ökonomie des Theaters?». En SCHUCHARDT, Beatrice y Urban, Urs (eds.). Handel, Handlung, Verhandlung. Theater und Ökonomie in der Frühen Neuzeit in Spanien. Bielefeld: Transcript, 2014, pp. 283-303. 